\section{$X$-Ray Sensitivity and Target Volume of Enzyme Induction}

THE enzyme activity of lysine decarboxylase after induction with L-lysine in non-growing Bacterium cadaveris (NCTC, 6578) increases nearly linearly with time ${ }^{1}$ until the final activity' level is reached. The 'final activity' and the 'induction rate'- the slope within the linear range of the activity curve in Fig. 1are characteristic for this strain and enzyme.

This investigation shows the inhibition on the

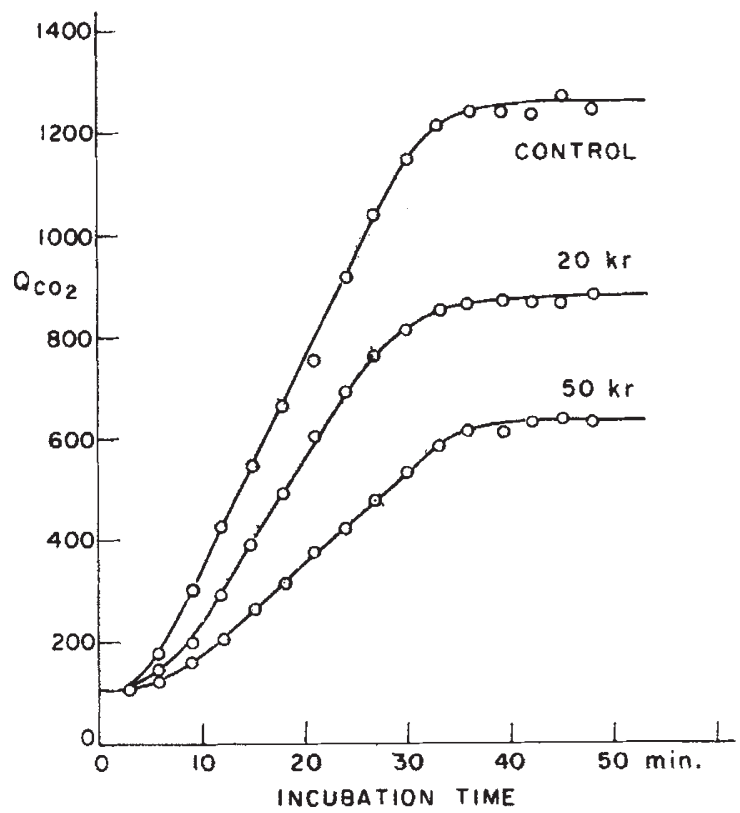

Fig. 1. Induction of lysine decarboxylase in $B$. cadaveris. The enzyme activity was measured manometrically at $30^{\circ} \mathrm{C}$. in 5 vol. carbon dioxide +50 mgm. glucose, $1.5 \mathrm{mgm}$. Difco yeast extract huffer about $5 \mathrm{mgm}$. wet bacteria. Induction by addition of and a out mit $\mathrm{QCO}$ in $\mathrm{mm}$. carbon dioxide developed by decarboxylation from lysine by $1 \mathrm{mgm}$. bacteria (dry weight) in $1 \mathrm{hr}$. X-irradiation with a beryllium window tube, $45 \mathrm{kV}$., $25 \mathrm{~m}$ :amp., additional $0.4 \mathrm{~mm}$. A filter; dose rate at $3 \mathrm{~cm}$. focus distance $2 \times 10^{4} \mathrm{r} . / \mathrm{min}$.

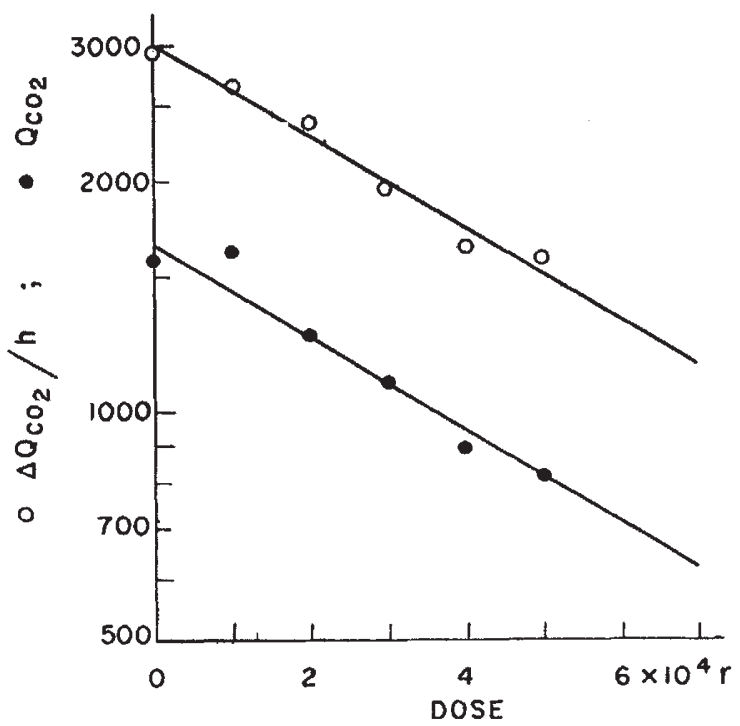

Fig. 2. Dose effect curve for the 'induction rate' $(O)$ and the "fleal activity' (•) induction process by $\mathrm{X}$-rays. After $\mathrm{X}$-irradiation the induction rate decreases by the same amount as the final activity, as can be seen in Fig. 1. The dose effect curves are plotted in Fig. 2. Both curves seem to be exponential. The inactivation dose is $7 \times 10^{4} r$. Since the inactivation dose of the enzyme molecule itself is $1.4 \times 10^{7} r$. - which is 200 times larger - the investigated effect on the induction is different from the X-ray effect on the already formed enzyme molecule within the cell. According to Pollard et al. ${ }^{2}$ an inactivation dose of $7 \times 10^{4} \mathrm{r}$. corresponds to a molecular weight of the radiosensitive unit of 20 million. The identical radiosensitivity of the 'induction rate'-which is essentially a velocity of the protein synthesis--and the 'final activity'- which is the amount of the end-product of the synthesis-suggest a possible mechanism of the induction. The mentioned identity of the dose effect curves could be explained by the assumption, that in each cell, one or several synthetic centres exist, and each centre will produce only a certain number of enzyme molecules. The single unit would be destroyed by a single hit.

This hypothesis agrees with the recent findings of Novick $^{4}$ for the induction of $\beta$-galactosidase in Escherichia coli. The target volume corresponding to a molecular weight of 20 million, and the nucleic acid inactivation spectrum for the induction ${ }^{4}$ leads to the conclusion that a complex nucleic acid structure is involved in enzyme induction. Approximately the same target volume has been found by Pollard ${ }^{5}$ for the induction of $\beta$-galactosidase in Escherichia coli.

I wish to thank Prof. Dr. B. Rajewsky for his interest and continued encouragement.

Max-Planck-Institut für Biophysik,

$$
\text { Helmut Pauly }
$$

1 Mandelstam, I., J. Gen. Microbiol., 11, 426 (1954).

Prog. Biophysics, 5, 72 (1955).

Pauly, H., Rajewsky, B., and Bücker, H., Arch. Biochem. Biophys. (in the press).

ick, A. (personal communication).

s (personal communication).

\title{
HAMATOLOGY
}

\section{Growth-Controlling Action of Human Serum in Cell Culture}

IT is reasonable to think that there are stimuli and opportunities in every human life which result in a cancerous transformation of some cells. The main factor in the progress of these cells to the clinical tumour stage might be a deficiency in the growthcontrolling defensive mechanism. To demonstrate the possible existence of such factors we have studied since 1955 the effect of human serum on different cells in cell culture ${ }^{1}$.

HeLa cells, a continuous amniotic cell line $(C A L)$ and primary amnion cell cultures were used. Briefly, the technique was as follows: HeLa and $C A L$ cells were cultivated in Roux bottles containing 30 per cent active human serum in Hanks solution; cell inocula were prepared by trypsinization and were cultivated in different 30 per cent human sera in Hanks solution in test-tubes. The following details are of importance for reproducible results: the inocula must be prepared from young, 1-2 day-old cultures, in excellent condition. The $p \mathbf{H}$ of the system must be controlled in all phases of the experiment (it may not exceed $7 \cdot 7$ ). The technique of cultivation of amniotic cells has been reported elsewhere ${ }^{2}$.

Using this technique, we observed that there are great differences between fresh human sera: the mode of 